\title{
CONTRIBUIÇÕES DA ECONOMIA PARA A RESOLUÇÃO DE LITÍGIOS
}

\author{
MORAES, Ana Paula Bagaiolo
}

RESUMO: O artigo tem por objetivo apontar quais benefícios podem ser auferidos para o Direito quando se promove a integração entre Direito e Economia, sobretudo quando se trata da resolução de litígios pelo Poder Judiciário brasileiro. Ademais, o trabalho visa mostrar como a interação entre essas ciências se dá na França e quais experiências o Brasil poderia extrair disso.

Palavras-Chave: Direito. Economia. Poder judiciário. Brasil. França.

SUMMARY: This article aims to point out what benefits can be earned when one promote the connection between law and economics, especially when it comes to dispute resolution at the Brazilian judiciary. Further, the work aims to show how the interaction between these sciences takes place in France and which experiences Brazil could extract it.

Keywords: Right. Economy. Judicial power. Brazil. France

\section{INTRODUÇÃO}

O Sistema Judiciário brasileiro encontra diversas falhas em seu funcionamento; por vezes a queixa é a respeito da morosidade para o alcance das decisões, pelos altos custos processuais; enfim, os problemas enfrentados pelo Poder Judiciário do Brasil são incontáveis, e os prejuízos consequentes são sociais e econômicos.

Apesar dessas falhas, pouco se sabe efetivamente sobre as consequências econômicas que essa problemática constitui, pois raros são os estudos ainda nesse sentido.

Desta feita, a proposta da presente leitura é a de verificar qual a visão da França com respeito ao funcionamento do Poder Judiciário e quais foram os apontamentos sobre essas deficiências na resolução de litígios, já que se trata de um país cuja cultura é a do Direito Codificado, como no Brasil.

\section{DO ESTUDO DE DIREITO E ECONOMIA}

O estudo de Direito e Economia precisa ser melhor compreendido antes de se levar adiante a discussão acerca das contribuições que a matéria pode trazer sobre a resolução de litígios, razão pela qual faz-se importante saber a história da matéria, seu desenvolvimento e suas contribuições para a ciência jurídica.

Apesar de ainda pouco explorada, a relação entre o Direito e a Economia é antiga, conforme observa Rachel Sztajn. Segundo a autora, já no século XVIII, Adam Smith e Jeremy Bentham estudavam e demonstravam a importância da análise multidisciplinar e interdisciplinar de fatos sociais, envolvendo Direito e Economia (SZTAJN, 2005, p. 74).

Na mesma esteira ensina Mackaay (2010, p.3), ao afirmar que Adam Smith seria o precursor dos estudos de Direito e Economia quando associa o utilitarismo à legislação em sua obra Inquiry into the Nature and Causes of the Wealth of Nations, uma vez que, nela, resta demonstrada a importância

\footnotetext{
${ }^{1}$ Faculdade Dr. Francisco Maeda
} 
da economia política na produção legislativa.

Assim, a economia política vem iluminando a análise dos institutos jurídicos sob a ótica econômica já há muito tempo, tendo seu início a partir de sua intervenção para o estudo e regulação do funcionamento dos mercados com Adam Smith.

Todavia, a interdisciplinaridade entre Direito e Economia ficou por muito tempo restrita apenas às questões de antitruste, regulação de mercados e cálculo de danos monetários (SALAMA, 2010), passando a matéria a ganhar espaço e respeito no meio acadêmico a partir dos anos 60, com a matéria Law and Economics, desenvolvida a partir dos escritos de Ronald H. Coase, Richard Posner, Guido Calabresi, Henry Manne, George Stigler, Armen Alchian, Steven Medena, Oliver Williamson, dentre outros (SZTAJN, 2005, p. 74).

Pelo exposto, é possível verificar que o movimento do Law and Economics nasceu a partir dos estudiosos oriundos do sistema da Common Law e se diversificou em diversas vertentes, dentre as quais Bruno Meyerhof Salama (2010) cita: Escola de Chicago, Escola de New Haven, Escola Austríaca, Escola Institucionalista e a Escola Neo-Institucionalista.

Apesar dessas diversas formas de se analisar o Direito sob a égide da Economia, a discussão contemporânea dessa matéria surgiu a partir de Ronald Coase, Guido Calabresi e Trimarcchi, e, posteriormente, foi desenvolvida por Richard Posner, Gary Becker e Henry Manne, com a Análise Econômica do Direito das Organizações.

Há que se ressaltar, todavia, que, não obstante os estudos iniciais de Direito e Economia tenham ocorrido na cultura do Direito Consuetudinário, vários países passaram a utilizá-lo e estudá-lo, especialmente nos países europeus ${ }^{2}$, cuja cultura é, em sua maioria, a do Civil Law.

Diversas são as possibilidades de auxílio do estudo interdisciplinar das referidas matérias; e, conforme ensina Rachel Sztajn, o objetivo de conjugá-las seria o de ter "a percepção da importância de recorrer a alguma espécie de avaliação ou análise econômica na formulação de normas jurídicas visando a torná-las cada vez mais eficientes" (SZTAJN, 2005, p. 75), ou seja, tornar eficiente todo o arsenal jurídico por meio da análise empírica usada pela Economia a fim de propiciar o melhor funcionamento do Sistema Judicial.

Apesar de muitos juristas questionarem a validade do diálogo entre as matérias, em virtude de elas possuírem diferenças metodológicas, David D. Friedman (2000, p. 8), demonstra que, partindo

da premissa de que as pessoas agem racionalmente, conclui-se que elas responderão melhor a incentivos externos que induzam a certos comportamentos mediante sistema de prêmios e punições. Ora, se a legislação é um desses estímulos externos, quanto mais forem as normas positivadas aderentes às instituições sociais, mais eficiente era o sistema.

Com isso, cai o argumento de que as diferenças metodológicas entre as duas ciências seriam insuperáveis, de maneira que é possível tirar dos ensinamentos econômicos uma maneira de "enriquecer a

\footnotetext{
${ }^{2} \mathrm{O}$ autor Bruno Meyherhof Salama destaca os seguintes países e institutos de pesquisa: “o Institut fur Recht und Ökonomik (Hamburgo, Alemanha), o Institut fur Genossenschaftswesen (Munster, Alemanha), o Forschungsstelle fur die oekonomische Analyse des Rechts (Saarbruecken, Alemanha), o Max-Planck Institute for Research into Economic Systems (Jena, Alemanha), o Institut fur Recht und Oekonomik (Kassel, Alemanha), o Instituto de Derecho y Economía da Universidad Carlos III (Madrid, Espanha), o Centre of Advanced Studies in Law \& Economics, Universiteit van Gent (Gent, Bélgica), o Rotterdam Institute of Law and Economics (Roterdã, Holanda) e a Libera Università Internazionale degli Studi Sociali Guido Carli (Roma, Itália). Desde 1990, o renomado programa de mestrado em Direito e Economia (Erasmus Program in Law \& Economics) ocorre simultaneamente nas universidades de Bolonha, Hamburgo, Roterdã, Ghent, Hamburgo, Aix-en-Provence, Haifa, Estocolmo, Madrid, Manchester e Viena." In: SALAMA, Bruno Meyerhof. Op. cit. 
gramática jurídica integrando a discussão da eficiência na discussão do justo.” (SALAMA, 2010).

Desta feita, é possível vislumbrar a notória contribuição que a disciplina vem trazendo para os problemas jurídicos, algo que certamente esbarra, inclusive, na questão da eficiência da resolução de litígios pelo Poder Judiciário. Tal questionamento se dá em virtude da morosidade na solução judicial de um processo e, também, pelo excessivo número de processos ajuizados a cada dia, situação esta que piora ainda mais a perspectiva de se encerrar uma lide.

Uma vez demonstrada a importância da matéria e sua extensa aplicabilidade no meio jurídico, resta agora o seguinte questionamento: como a referida disciplina pode influenciar no funcionamento da justiça? É o que se busca responder por meio do presente trabalho.

\section{DOS ESTUDOS DE DIREITO E ECONOMIA NO BRASIL E NA FRANÇA}

A insatisfação para com o funcionamento da justiça no Brasil é algo notório. A insatisfação da sociedade brasileira como um todo foi medida e citada no trabalho de Armando Castelar Pinheiro por meio de dados estatísticos fornecidos pelo Vox Populi e pelo IBGE, de modo que, em Abril de 1999, 58\% dos entrevistados consideravam a Justiça brasileira incompetente, enquanto $34 \%$ a julgavam competente; em Abril de 1999, 89\% dos entrevistados disseram que a Justiça brasileira era demorada, enquanto apenas $7 \%$ a julgavam célere; em 1993, 87\% dos brasileiros acreditavam que o problema do Brasil não estaria nas leis, mas sim na Justiça, que consideravam lenta (PINHEIRO, 2005, p. 246).

A referida situação do Sistema Judiciário resulta em efeitos de ordem social e econômica, razão pela qual não se pode afastar a análise econômica dessa realidade. Stigler, citado por Armando Castelar Pinheiro (2000, p. 13-14), aponta três áreas em que o direito e a economia podem interagir:

\footnotetext{
Primeiro, os economistas têm tradicionalmente assessorado tribunais e advogados em casos ati-truste e anti-dumping e em outros tipos de litígio no comércio internacional, bem como em casos decorrentes da implementação da política econômica de uma maneira geral. Segundo, a economia ajuda na compreensão tanto dos incentivos ao litígio, como do comportamento das partes durante o próprio processo de litígio e dos custos envolvidos. A terceira (...) refere-se à análise do papel das instituições judiciais na determinação do ritmo e da forma do desenvolvimento econômico dos países.
}

Assim, por meio dessas possíveis formas de interação entre o Direito e a Economia, é possível estudar formas para tornar o funcionamento da justiça mais eficiente no Brasil.

A pergunta que se pode fazer é a seguinte: como essa análise econômica sobre o Poder Judiciário pode beneficiar o funcionamento da justiça no Brasil? Como isso ocorre em outros países?

A maioria da bibliografia que se encontra acerca desse tema é escrita por doutrinadores cuja origem é a da cultura do Direito Consuetudinário, razão pela qual, por vezes, seria possível questionar a aplicabilidade dessas soluções no Brasil, cuja cultura é a do Civil Law.

A fim de tentar dirimir essa questão, tomar-se-á como exemplo a França, país que traz, em sua extensa pesquisa, ensinamentos aplicáveis para a realidade brasileira, haja vista que também guarda problemas em seu sistema judicial e que, ainda, tem também seu direito codificado.

Acerca dos problemas referentes ao judiciário francês, a autora Nathalie Chappe $(2005$, p.1) cita as recriminações feitas ao sistema judicial de resolução de litígios na França, apesar de todo o investimento financeiro feito ao setor.

Há que se destacar que, de maneira geral, o diálogo entre Direito e Economia é ainda uma área que não convence a alguns juristas, que se negam a relacionar as ciências sob o argumento de que as diferenças metodológicas entre elas seriam insuperáveis (SZTAJN, 2005, p. 75). 
Ressalta o autor Lionel Montagné (2010) que, especialmente na França, existem dificuldades na aceitação da interdisciplinaridade das ciências. Não obstante ele reconheça a importância do estudo para a compreensão da lógica das normas jurídicas e das decisões judiciais, explica, com pesar, que o interesse pela pesquisa nessa seara e o reconhecimento de sua importância é ainda muito pequena.

Nathalie Chappe (2005, p. 2), por sua vez, também explica que os estudos de Direito e Economia, não obstante sejam bem recebidos e aprofundados nos países anglo-saxões e na Europa continental, ainda não foram reconhecidos pela França:

L'analyse économique du droit est ainsi devenue une discipline foisonnante dans les pays anglo-saxons et dans la plupart des pays d'Europe continentale (Allemagne, PaysBas, Belgique, Italie, Espagne...). Toutefois, elle reste un parent pauvre de l'économie em France et ne semble pas percer dans les milieux juridiques du fait du cloisonnement excessif de l'économie et du droit.

Apesar dessa referida relutância no estudo da disciplina, já se pode encontrar diversas obras sobre os estudos que relacionam Direito e Economia, estudos estes cujo intuito é o de melhorar a qualidade do funcionamento do judiciário na França.

O Brasil, na mesma esteira, possui diversos autores que tratam da matéria, especialmente quanto à análise do papel das instituições judiciais no desenvolvimento econômico do país, valendo-se dos trabalhos de Ronald Coase, Guido Calabresi e Trimarcchi e, especialmente, na Teoria das Organizações ${ }^{3}$.

Os esforços dos estudiosos franceses no sentido de apresentar medidas eficazes para a solução de seus litígios são de grande relevância, razão pela qual será de grande valia apresentá-los para que, dentro do possível, vislumbrem-se quais das conclusões desses trabalhos podem ser aplicados ao Brasil.

\section{A ANÁLISE ECONÔMICA DA RESOLUÇÃO DE CONFLITOS JURÍDICOS NA FRANÇA}

Consoante os ensinamentos de Bruno Deffains (1997, p. 57), o Direito se ocupa não apenas do impacto das normas jurídicas na escolha dos agentes, mas, ainda, em como os agentes a ela submissos interagem.

Nessa esteira, a interação das partes e o processo cognitivo que as leva a propor uma ação ou até mesmo a transigir em uma demanda judicial é, sem dúvida, um fator que interfere no funcionamento do judiciário e, portanto, merece ser estudada.

A partir da iluminação econômica sobre o assunto, é possível verificar formas mais efetivas para o autor, réu e advogados no momento de ajuizar a ação e, inclusive, de firmar acordos antes da sentença judicial, elementos que, quando bem utilizados, podem colaborar para desafogar o número de processos que hoje aguardam uma decisão e, ainda, evitar a propositura de novas lides, especialmente as infundadas.

Um exemplo disso, trazido por DEFFAINS (1997, p. 88), é quanto à atribuição das custas processuais influenciando a decisão das partes no momento da propositura da ação e, ainda, o que leva o sujeito a propor uma ação puramente visando uma "aventura jurídica".

Três questões são levantadas pelo autor (DEFFAINS, 1997, p. 89) como causa para a ocorrência desses eventos: a assimetria de informação das partes; os intermediários jurídicos, ou seja, os advogados; e o impacto do contencioso na precaução dos agentes.

Quanto à assimetria de informações, o referido autor afirma que os doutrinadores, de modo geral, não se atentam para os tipos de assimetrias de informações capazes de influenciar o comportamento das partes no momento da negociação.

${ }^{3}$ A exemplo disso, é possível citar autores como Rachel Sztajn, Décio Zylbersztajn, Armando Castelar Pinheiro e ainda muitos outros que vêm trabalhando com a análise econômica do Direito.

Nucleus,v.13,n.2,out..2016 
Na maioria das vezes, ele continua, apenas supomos que o autor saberia apenas o montante de seu prejuízo e/ou que o réu saberia somente se sua responsabilização pelo ato é possível, nos termos de seus esforços para evitá-lo antes de sua ocorrência. Ora, se essas informações forem voluntariamente reveladas com credibilidade pelos litigantes, certamente não haverá um julgamento, porque as partes serão capazes de entrar em acordo (DEFFAINS, 1997, p. 89)

A partir dessa informação, o autor dá ênfase às assimetrias dessas informações diante da preferência das partes em face do risco, haja vista que elas são difíceis de serem expostas de uma forma confiável no processo. Explora-se, assim, o réu com uma visão neutra em face ao seu risco no processo e um autor também desconhecedor dos riscos do processo ou que sente aversão pelo risco (DEFFAINS, 1997, p. 89).

Nesse caso, Deffains (1997, p. 89) adverte que quando o autor da ação conhece os seus riscos, a negociação pode falhar se o réu fizer uma proposta visando distinguir com qual tipo de autor está lidando: se o propositor da ação tiver medo dos riscos processuais, aceitará a proposta; todavia aquele que for indiferente ou neutro em face desses riscos, a rejeitarão. Com isso, a estratégia dos réus será no sentido de levar adiante apenas o processo em face de autores indiferentes aos riscos de perder a ação:

Dans l'hypothèse où le plaignant est seul à connaître son attitude vis-à-vis du risque, la négociation peut échouer si le défendeur fait une proposition visant à distinguer les deux types de plaignants, c'est-à-dire une proposition que les individus éprouvant de l'aversion pour le risque accepteront, mais que ceux qui sont neutres vis-à-vis du risque rejetteront. À l'équilibre, la stratégie des défendeurs conduit donc à un procès uniquement contre les plaignants indifférents au risque.

A partir disso, o que se conclui é que os autores indiferentes aos riscos processuais podem esperar um ganho superior em relação àqueles que transacionaram, já que optaram por finalizar o processo.

Essa realidade, para as seguradoras, é frequente nos contenciosos civis. As empresas de seguro se utilizam dessa lição quando atuam como rés na ação, porque representam aqueles que gerem uma carteira amplamente diversificada de riscos, enquanto os autores são, na maioria das vezes, partes inexperientes. $\mathrm{O}$ efeito imediato disso é que as seguradoras se tornam intransigentes no momento de fazer um acordo e acabam lucrando com isso.

Acerca dos intermediários da justiça, ou seja, dos advogados; a análise da resolução de conflitos pressupõe que as partes estão em contato direto, sem levar em consideração a possibilidade de assimetria de informações entre eles: tanto o cliente pode estar melhor informado que seu advogado sobre os fatos do processo e, assim, consequentemente, de suas chances de ganhar o processo como também, por outro lado, o advogado por estar melhor informado que seu cliente acerca de seus esforços e sua competência para a atuação na ação (DEFFAINS, 1997, p. 91).

O problema apresentado pelo autor é, assim, sobre a convenção dos honorários advocatícios e o momento de seu recebimento como fator influenciador da prestação de serviços do advogado.

Nesse ínterim, ele faz uma severa crítica ao sistema de quota litis, ou seja, aquele em que o honorário percebido pelo advogado é determinado pela porcentagem dos ganhos do cliente em sua atuação na ação, esclarecendo, inclusive, que esse sistema é proibido em diversos países, como a Grã-Bretanha e a própria França (DEFFAINS, 1997, p. 91).

Sua crítica é baseada nas seguintes questões: ao financiar o contencioso, o advogado poderia favorecer o aparecimento de ações indesejáveis; por vezes o honorário de resultados pode ser estabelecido de forma excessiva e, ainda, porque o interesse do advogado na ação poderia provocar um conflito de interesses para com o cliente e impossibilitar a negociação de um acordo (DEFFAINS, 1997, p. 91). 
Por outro lado, outras críticas são feitas aos demais sistemas de pagamento de honorários. No tocante aos honorários pagos por hora, pode haver um menor esforço por parte do advogado e maiores possibilidades de perda diante dos tribunais; sem contar que o cliente poderá pagar apenas até o momento em que a sua margem de ganho não ultrapasse o montante dispensado com o seu procurador (DEFFAINS, 1997, p. 92).

Ainda tratando das críticas, acerca dos honorários proporcionais, fica nas mãos do advogado a decisão do tempo que gastará cuidando da ação conforme os ganhos que espera, ou seja, poderá haver de sua parte um esforço menor e, consequentemente, a menor probabilidade de ganho da ação (DEFFAINS, 1997, p. 92).

Todavia, P. M. Danzon (1983, p. 213-284), citado por Deffains (1997, p. 92), demonstra que essas duas visões radicais são incorretas porque:

competition in the market for legal services can lead attorneys paid on contingent basis to act exactly as would be preferred by fully informed clients paying na hourly wage. If competition is imperfect, however, there may some tendency toward less attorney effort than the client would prefer.

Com isso, em havendo competição na prestação de serviços entre os advogados, haverá a possibilidade de se dirimir a hipótese de um menor desempenho em sua atuação quando a forma de pagamento for por hora ou por honorários proporcionais.

Importa ressaltar, contudo, o que o sistema de quota litis pode trazer como consequência quando utilizado, nos termos expostos por Deffains (1997, p. 92):

[...] le nombre de plaintes déposées sera certainement plus eleve avec la pacte de quota litis, non parce que CE système incite à déposer des plaintes superficielles ou parce que les honoraires sont excessifs, mais parce qu'il protège le client contre le risque.

Desta feita, o que se afirma é que, quando o litigante não encontra riscos ao propor sua demanda, ele certamente não terá cuidado ao propor-la, independentemente da forma como seu advogado será remunerado; com a ressalva de que, entretanto, o sistema quota litis favorece a redução dos riscos da parte e, por conseguinte, motiva-o a propor diversas ações.

Em contrapartida, Miceli (1991, p. 381-399), citado por Deffains (1997, p. 92-93), “estiment en outre que ce système contribue à réduire le nombre de procès si la tendance des victimes d'accidents à intenter une action en justice incite les auteurs de dommages à prendre plus de précaution”, ou seja, ao mesmo tempo essa forma de honorários pode incitar maiores proposituras de ações, pode, ainda, fazer com que potenciais causadores de danos sejam mais cautelosos diante da possibilidade de serem acionados.

Por fim, quanto ao impacto do contencioso na precaução dos agentes, o que argumenta é que, em virtude de os processos serem custosos, seria possível pensar em direcionar os gastos desses litígios e do montante condenatório para a prevenção de atos que suscitem a propositura de ações judiciais (DEFFAINS, 1997, p. 93).

Entretanto, mister salientar que, para saber quais seriam os custos da prevenção desses atos lesivos, seria preciso lançar mão da pesquisa empírica e matemática da Economia.

Tratando ainda da possibilidade de se buscar a melhor eficiência do funcionamento do judiciário por meio do estudo de Direito e Economia das partes envolvidas no processo, Nathalie Chappe (2005, p. 3-4) discorre que a eficácia do sistema jurídico será avaliada conforme a minimização do custo social dos conflitos, algo que abarca os custos administrativos, suportados pelos litigantes para assegurar sua participação de forma adequada na ação e, ainda, o que ela chama de "custos do erro", representados pelas 
falhas cometidas pelo Poder Judiciário, lembrando que, para medi-los, seria preciso um julgamento de referência, ou melhor, um paradigma, a fim de que os economistas possam, assim, mensurar as medidas corretivas para a redução dos custos associados à resolução de litígios. Um exemplo proposto pela autora que gera a redução total de custos seria a adoção de medidas alternativas de resolução de litígios.

Ensina também a autora que, por vezes, o comportamento racional no âmbito privado pode ser, na esfera coletiva, irracional; de modo que tal dicotomia se manifesta tanto no momento da escolha de ajuizar ou não uma ação quanto no momento de decidir entre fazer um acordo ou levar o processo adiante (CHAPPE, 2005, p. 77).

Em matéria de ajuizamento de uma ação, duas são as possibilidades: primeiro, que muitas das ações propostas o são porque o autor não considera as consequências de seu ato, assim o incentivo individual é maior que o social; mas tudo isso sem medir sequer os próprios gastos que terá com a demanda judicial ou ainda os gastos que o Estado terá a nível coletivo. O mesmo pensamento no sentido inverso pode também ser aplicado: a motivação social pode, às vezes, ser maior que a motivação individual na propositura da ação, porque o litigante pode contribuir para com a credibilidade do sistema judicial ao propor uma ação que será mais benéfica para a sociedade do que para ele mesmo (CHAPPE, 2005, p. 77).

No tocante às negociações para se chegar a um acordo judicial, elas podem ser feitas tanto para atender os interesses individuais quanto aos coletivos. A decisão de fazer ou não uma transação tem custos e benefícios que devem ser considerados no momento da decisão (CHAPPE, 2005, p. 77).

É possível que um acordo possa representar o bem estar individual e social; lembrando que, quando há uma transação judicial, os custos suportados pela coletividade pelo funcionamento do judiciário é reduzido, portanto essa hipótese seria melhor do ponto de vista da sociedade. Por outro lado, diversos acordos impensados podem diminuir o comportamento prudente das partes e, inclusive, limitar a propositura de ações que poderiam trazer benefícios para a coletividade (CHAPPE, 2005, p. 77).

Hoje, as políticas públicas em matéria de resolução de litígios seria essencialmente voltada para a regulação da demanda pela utilização do serviço judicial. Entretanto, para a autora, na prática, seria preciso que as medidas públicas interviessem na decisão de se ajuizar ou não uma ação no sentido de aproximar as motivações individuais e sociais e, ainda, que interviessem também no momento da escolha da substituição de um litígio por uma resolução alternativa (como a arbitragem, por exemplo), que seria menos custosa (CHAPPE, 2005, p. 78).

Outra análise que merece ser apresentada pelos estudiosos franceses é a influência do excessivo número de demandas judiciais no Poder Judiciário na decisão de ajuizar uma petição ou de resolver a demanda amigavelmente.

Nathalie Chappe (2010) aduz, em síntese, que o atraso nas decisões judiciais é um problema que indetermina o funcionamento das cortes, influencia a efetividade do sistema ao protelar a sanção e tira a credibilidade e a confiabilidade do sistema de modo geral.

As medidas políticas apresentadas como solução para esses problemas são diversas, de modo que a autora cita o aumento do número de juízes, mudanças no procedimento judicial, adoção de medidas alternativas de resolução de litígios, etc. (CHAPPE, 2010); todavia essas soluções para a morosidade da justiça não têm surtido efeito.

Por meio da análise econômica do sistema judicial, a autora explica que, sob a ótica das partes litigantes, a morosidade da justiça pode representar, na verdade, um incentivo para a propositura de novas demandas.

Isso se dá porque o indivíduo, ao saber que existe a demora para a solução judicial, pode se sentir movido a praticar atos lesivos contra outrem, de modo que, sem reformas nas custas judiciais da 
propositura da ação e nem na diminuição dos valores das sentenças condenatórias, provavelmente o número de demandas não vai diminuir (CHAPPE, 2010):

The contribution of the paper is to investigate the relationship between congestion and the behavior of litigants. We have developed the idea that court congestion affects not only the plaintiff's decision whether to file a lawsuit, but also the defendant's decision whether to do the act resulting in liability. We have demonstrated that the interactions among the level of congestion, the plaintiff's decision to sue, and the individual's decision to commit an illegal act can be intricate. Consequently, unless judicial reforms take into account the presence of congestion, raising filing fees or decreasing the level of awards may have unintended consequences. Contrary to Verreck and Muhl (2000) we cannot recommend the systematic use of higher court fees in order to reduce delay. At first the authorities should evaluate different parameters (among others the impact on the probability that the plaintiff will sue the defendant) in order to know the global impact of an increase in court fees. (...) In this case, higher court fees mean weaker probability of facing suit and so reduce the costs of trial for defendants. More defendants will do harmful act. Globally, we will have more litigation.

The traditional answer to court congestion is more judges. Our model allows us to analyze this delay-reduction form. Again our results (...) suggest that this measure may have perverse effect. Indeed, increasing the number of judges reduces the congestion cost and thus induces more plaintiffs to sue the defendant. According to the impact on the behavior of the defendant (...), the measure can result in an increase in the demand for litigation.

Com isso, é possível concluir que os estudos de Direito e Economia podem promover a melhora do funcionamento judicial, tanto que seus ensinamentos estão sendo amplamente divulgados e, ainda que tardiamente, podem auxiliar na melhor prestação do serviço judicial na França.

\section{APLICAÇÃo DA ANÁLISE ECONÔMICA DA RESOLUÇÃo DE CONFLITOS PARA O BRASIL}

Assim como na França, os estudos acerca da assimetria das informações pode ser de grande valia para os contenciosos no Brasil. Nos termos anteriormente expostos, em havendo tal assimetria de informações, é possível coibir o prosseguimento de ações que representam verdadeiras "aventuras jurídicas" a partir do conhecimento da visão que as partes têm do risco processual envolvido.

A melhor forma de se ponderar isso é com o bom-senso do magistrado no momento da audiência de conciliação; ele deve verificar, pelo proceder das partes (sobretudo do autor) quais são suas atitudes com relação aos riscos do processo, buscando, assim, incentivá-las a firmar um acordo, por exemplo. $\mathrm{O}$ mesmo pode ocorrer quando uma das partes for uma seguradora, como no caso citado anteriormente; o juiz deve ser um bom mediador e, dentro do possível, motivar as partes a transigirem.

Acerca dos apontamentos que envolvem os procuradores do processo, no Brasil a questão demandaria estudos empíricos para que se saiba até que ponto a forma de pagamento de honorários advocatícios pode influenciar no número de demandas propostas, uma vez que a legislação vigente abarca os pagamentos de honorários legais e convencionais; sem contar o fornecimento da justiça gratuita para os que não podem arcar com as custas judiciais e, ainda, com os advogados nomeados àqueles que não podem pagar por seus honorários. ${ }^{4}$

Desde já, o que se pode aprender com os ensinamentos de DEFFAINS (1997) nesse sentido é que os juristas brasileiros precisam estar atentos aos riscos que as partes litigantes têm no momento da propositura da ação, a fim de que, assim, não se incorra na possibilidade de aumentar o número de processos judiciais indesejáveis e desnecessários.

\footnotetext{
${ }^{4}$ Vide artigos 19 a 35 do Código de Processo Civil brasileiro.
} 
É preciso, assim, que, por meio da pesquisa empírica iluminada pelos ensinamentos econômicos, seja possível medir o grau do risco enfrentado pelo autor da ação e os reflexos disso para o número de ações propostas, sobretudo na Justiça do Trabalho, em que o reclamante jamais arca com os custos do processo e, em virtude disso, pode abrir uma demanda infundada para tentar extrair alguma coisa da parte reclamada.

Sobre o impacto do contencioso na precaução dos agentes, os ensinamentos extraídos pelo modelo francês são trazidos na íntegra, porque não obstante a idéia de prevenção seja motivadora, é preciso também quais seriam efetivamente os custos implícitos nisso, algo que será logrado por meio do auxílio da Economia.

No tocante às lições de CHAPPE (2005) sobre a aplicação de políticas públicas que promovam o equilíbrio entre os custos sociais e individuais da demanda judicial, é plenamente possível a sua aplicação no Brasil enquanto medida pública que represente motivação individual com benefícios sociais, mas não ainda com relação à escolha de procedimentos alternativos, como a arbitragem, porque ainda que elas sejam menos custosas, no Brasil ainda não se pode afirmar, com convicção que o número de Câmaras de Arbitragem e a sua respectiva qualificação seriam suficientes como na França para realizar essa empreitada.

Seria preciso, portanto, que se realizasse um estudo empírico para averiguar se o sistema arbitral brasileiro teria, hoje, as mesmas condições de atuar juntamente e, conforme o caso, até mesmo substituindo a lide judicial de maneira adequada.

Finalmente, acerca das medidas que envolvem a decisão da parte no momento de litigar e de firmar acordos judiciais mediante a morosidade e o alto número de processos do Poder Judiciário, a lição que se pode extrair dos estudos franceses é que, de fato, não de pode simplesmente aumentar o número de juízes atuantes e mudar os procedimentos judiciais sem analisar outras formas de se dirimir o problema.

É preciso que, a exemplo da França, o Brasil tenha estudiosos que possam verificar se o aumento das custas processuais e a diminuição dos valores pagos nas sentenças condenatórias podem auxiliar na redução da propositura de ações, especialmente aquelas que representam "aventuras judiciais" e são, portanto, indesejáveis.

\section{Considerações finais}

Conforme exposto, a disciplina de Direito e Economia tem suas raízes no Common Law; todavia é hoje amplamente reconhecida como área de estudo que pode auxiliar o funcionamento mais eficaz e com menores custos para a instituição judicial.

Os problemas do funcionamento judicial não são exclusivos de países cuja tradição é o direito codificado; a exemplo disso, foi citada a França, que também enfrenta toda sorte de morosidade e de elevados números de processos.

Entretanto, por meio das medidas propostas pelos estudiosos do Direito e Economia, é possível dirimir esses problemas, seja por meio da análise das partes envolvidas no processo; por meio de alterações nas formas como os honorários são pagos para os advogados; por meio também de políticas que promovam a busca pelo equilíbrio dos benefícios individuais e coletivos quando uma ação é proposta; ou, por fim, aumentando os custos envolvidos no ajuizamento de uma demanda e a reduzindo dos valores pagos em sentenças condenatórias.

Não se pode afirmar que todas as possibilidades apresentadas pelos juristas franceses poderão ser aplicadas sem reservas na realidade brasileira; todavia o que é preciso analisar é a contribuição que a matéria pode trazer para o Poder Judiciário como instituição; de modo que não se pode mais ignorar o Direito e Economia como importante ferramenta para melhorar os instrumentos jurídicos de acesso à justiça. 


\section{REFERÊNCIAS}

CHAPPE, N.. Court Congestion and the Decision to Litigate or Settle. Disponível em: <http://papers.ssrn.com/sol3/papers.cfm?abstract id=670682 >. Acesso em 05 ago. 2010.

CHAPPE, N.. Économie et résolution des litiges. Paris: Economica, 2005.

DEFFAINS, Bruno. L'analyse économique de la résolution des conflits juridiques. In: Revue française d'economie. Volume 12 n. 3, 1997.

FRIEDMAN, D.D. Law's Order: What economy has to do with law and why it matters. Princeton N. J., Princeton University Press, 2000.

MACKAAY, E.. History of Law and Economics. Disponível em:

<http://encyclo.findlaw.com/0200book.pdf>. Acesso em 15 ago. 2010.

MONTAGNÉ, L.. Law and Economics in France. Disponível em:

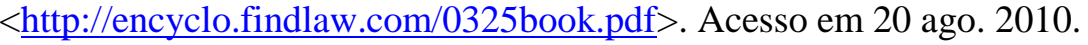

PINHEIRO, A.C.. Judiciário e economia no Brasil. São Paulo: Editora Sumaré, 2000.

PINHEIRO, A.C.. Magistrados, Judiciário e Economia no Brasil. In: Direito e Economia: Análise econômica do Direito e das Organizações. ZYLBERSTAJN, Décio; SZTAJN, Rachel. Rio de Janeiro: Elsevier, 2005. $2^{\mathrm{a}}$ reimpressão.

SALAMA, B.M.. O que é pesquisa em Direito e Economia?. Disponível em:

$<$ http://www.ordemlivre.org/files/Bruno_Salama-O_que_e_pesquisa_em_DE.pdf $>$. Acesso em: 10 ago. 2010.

SZTAJN, R.. Law and Economics. In: Direito e Economia: Análise econômica do Direito e das Organizações. ZYLBERSTAJN, D.; SZTAJN, R.. Rio de Janeiro: Elsevier, 2005. $2^{\mathrm{a}}$ reimpressão. 